\title{
Service Quality and Satisfaction Indices for China Passengers in the Souvenir Avenue at Taoyuan International Airport
}

\author{
Shiaw-Wuu Perng ${ }^{1}{ }^{*}$, Yu-Chieh $\mathrm{Cho}^{2}$, Tsung-Po Lo ${ }^{3}$ \\ ${ }^{1}$ Dept. of Air Transportation/Kainan University, Taoyuan, ROC \\ ${ }^{2}$ School of Tourism \& Transportation/Kainan University, Taoyuan, ROC \\ ${ }^{3}$ Customer Service \& Admin Dept./Tasa Meng Corporation, Taoyuan International Airport, ROC
}

Email address:

swperng@mail.knu.edu.tw (Shiaw-Wuu Perng), jessie920807@gmail.com (Yu-Chieh Cho), Shawn.ltp@gmail.com (Tsung-Po Lo) *Corresponding author

\section{To cite this article:}

Shiaw-Wuu Perng, Yu-Chieh Cho, Tsung-Po Lo. Service Quality and Satisfaction Indices for China Passengers in the Souvenir Avenue at Taoyuan International Airport. Science Innovation. Vol. 4, No. 4, 2016, pp. 221-227. doi: 10.11648/j.si.20160404.19

Received: September 25, 2016; Accepted: October 17, 2016; Published: October 19, 2016

\begin{abstract}
Chinese mainland tourists are important to tourism industry in Taiwan. The study objective is to analyze the marketing effects on satisfaction of Chinese tourists in the Souvenir Avenue at Taoyuan international airport. Research framework was based on the European EPSI rating system and SERVQUAL service factors. The multiple regression model was used to evaluate the six hypotheses of antecedent effects. The results showed that some hypotheses were supported. Avenue image and product quality were not significant antecedents. Tourists' expections had significant effect on their perceived value and satisfaction. Tourists' perceived value had significant effect on their satisfaction evaluation. The satisfaction level was an significant antecedent factor of tourists' purchase loyalty. Some perceived SERVQUAL factors were important antecedents of perceived value and satisfaction in the survey.
\end{abstract}

Keywords: Taoyuan International Airport, Souvenir, Satisfaction, Loyalty, Regression Analysis

\section{桃園機場伴手禮大街服務品質滿意度指標一以陸客為例}

彭效武 ${ }^{1 *}$, 卓鈺潔, 駱宗伯 ${ }^{3}$

1空運管理學系，開南大學，桃園市，中華民國

觀光運輸學院國際運輸組, 開南大學, 桃園市, 中華民國

${ }^{3}$ 免稅店公共服務部, 采盟股份有限公司, 桃園市, 中華民國

\section{邮箱}

swperng@mail.knu. edu. tw（彭效武），jessie920807@gmail.com（卓鈺潔），Shawn.1tp@gmai1.com（駱宗伯）

摘要：由於大陸是中華民國的主要國際觀光旅客來源之一, 因此本研究是探討在桃園國際機場第二期航廈伴手禮大街 的服務品質與伴手禮商品是否能夠滿足大陸來台旅客之需求。研究架構採用歐盟EPSI滿意度指標及SERVQUAL品質構面, 設計六項關連假設以進行複迴歸分析。研究結果顯示企業形象與商品本身對於認知價值、滿意度沒有顯著直接影響; 期望對於認知價值、滿意度有顯著直接影響; 認知價值對於滿意度有顯著直接影響; 滿意度對於忠誠度有顯著直接影 響; 部分的認知服務品質構面對於旅客認知價值、旅客滿意度有顯著直接影響。受訪之大陸旅客對於伴手禮大街的旅 客認知價值會有下列因素影響，包括旅客期望、服務有形性、服務可靠性、服務反應性、服務保證性及服務同理心。 旅客滿意度會受到旅客期望、服務有形性、服務可靠性及認知價值等因素的影響。 
矢键词: 桃園國際機場, 伴手禮, 滿意度, 忠誠度, 迴歸分析

\section{1. 研究動機與背景}

隨著全球化國際交流互動頻繁，國際間觀光旅遊活動 日趨熱絡且成長迅速，全球旅遊規劃業者Amadeus委託牛 津經濟研究院 (Oxford Economics), 預測旅遊產業趨勢, 未來十年內, 旅遊業年成長率將超過五\%, 比全球GDP成長 更快 (天下) [1]。

2013年，國際旅遊消費數據達到1兆1870億美元 (35 兆6100億台幣)，較經濟危機前一年的2008年，成長 2300 億美元 (6兆9千億台幣)（Traveladvertiser, 2015）［2］。英 國的Verdict零售業數位媒體公司的Global Airport Retailing (2015) [3]指出, 從2008年至2015年之間的每位 旅客平均花費均成長，亞洲地區從美金6.43成長至美金 8.5, 歐洲地區從美金6.38成長至美金6.26, 美洲地區從美 金2.68成長至美金 2.76 , 中南美洲地區從美金 13.62 成長 至美金14.80。

根據交通部統計，2015年來臺觀光人次可望突破千萬 大關，到了 2018 年，來臺觀光人次將再增加 170 萬人次, 外匯收入將突破新臺幣 5,000 億元。臺灣觀光產業蓬勃發 展, 也帶動伴手禮的商情隨之看漲 (中央通訊社, 2015) [4]。 在此趨勢下, 桃園國際機場於2015年9月10日在機場第二 航廈二樓推出「機場伴手禮大街 (Souvenir Avenue)」, 以時尚明亮的裝潢使整體空間煥然一新並結合國內知名 品牌公司最夯的伴手禮, 提供消費者多樣化的選擇, 讓出 入境旅客可以在機場停留時選購好吃的伴手禮, 送接機國 人也能享受購物樂趣。有關新的購物商街, 對於吸引旅客 購買伴手禮的影響, 尚未有文獻探討, 也是本研究的研討 對象伴手禮大街。因此, 希望藉由本研究來開起探討伴手 禮大街的旅客意見調查。

挑選伴手禮是享受旅遊樂趣中的一環, 來台旅 客對台灣伴手禮的偏好為何? 美食滔客 (2015) [5]於 2015年7月 16 日指出亞洲遊客來台最愛的十大伴手禮, 鳳 梨酥穩坐冠軍寶座, 日本、韓國與大陸旅客伴手禮排名各 有不同, 大陸旅客偏愛台灣的麻糬及牛軋糖; 日本旅客偏 愛月餅、泡麵、調味料、蜜餞及台灣茶; 韓國旅客則是偏 愛台灣的奶茶、蛋捲、芋頭酥以及水果口味的啤酒。

旅客是消費族群之一，其滿意度可以明顯影響其購買意 圖及忠誠度, 綜觀國內已有相當多研究單獨使用滿意指標模 式的研究, 較多針對咖啡連鎖店、百貨公司、健身中心、手 機電信業、科學工業園區等相關探討, 但對於旅客的類似研 究也極為稀少, 而對桃園國際機場伴手禮大街之大陸旅客對 伴手禮滿意度調查, 目前仍閣如。因此本研究是以建構及分 析在桃園國際機場二期航廈購物的大陸旅客對伴手禮大街 商家產品滿意度，以作為台灣美食行銷介紹參考。

\section{2. 文獻回顧}

本研究主要探討桃園機場伴手禮大街的商品與服務 是否可以滿足大陸旅客之期望。因此, 針對本研究首先回
顧伴手禮相關文獻來了解伴手禮為何、在顧客期望與認知 品質、顧客滿意度及忠誠度相關文獻來進行回顧, 最後針 對本研究參考的EPSI架構相關文獻來進行梳理回顧。

\section{1. 伴手禮品質}

\subsection{1. 伴手禮的定義}

伴手禮 (Souvenir) 觀念源自人類社會文化中，人際交 往表達情意的生活習慣, 其一詞源自閩南語。「伴手」形 容拜訪親友時, 不是「空手」而來, 而方便的帶些隨手可 攜帶的禮物到訪, 及古人「伴禮」之意 (陳明國等人, 2013）[6]。伴手禮是出門到外地時, 為親友買的禮物, 一 般是當地的特產或是諸如地標模型、裝束等富含特色的產 品。舉凡外出或回鄉之民, 為表達濃情之意, 往往會攜手 帶禮, 不論為具實用性、品嚐性或收藏性之禮品, 皆代表 著人際間情感之聯繫(簡南山與賴宏榮，2009）[7]。旅遊 伴手禮為購買者在旅遊當下購買該物件, 且被帶回原居住 地作為禮物贈送或自用, 一方面能分享旅遊經驗維繫親友 情感, 再者也可自用品嘗或回憶留念 (林雅涵, 2014) [8]。

\section{1.2. 伴手禮的商品特性}

伴手禮的特性部分, 大部分都提到關於品質、價錢與 選擇性。Littre11等人 (1994) [9]強調遊客對於產品特性的 判糹標準包括圖案、優越質感的手工作品以及迷人的色澤。 有些遊客可能會被伴手禮的天然性、出產國家等產品屬性 吸引; 其他遊客則在乎伴手禮清潔與照顧的難易度、象徵 旅遊地、美學與功能性, 以及是否為當地知名工匠現場製 作的作品。Turner與Reisinger (2001) [10]提出三項對遊客 而言重要的產品屬性, 分別為: 價值（等級、品質）、產 品顯露的特徵（顏色、展示及大小）以及獨特性。Littrel1 等人 [9] 也認為伴手禮本身所具有的特性會影響消費者的 購買意圖, 如伴手禮本身的獨特性 (uniqueness) 為何, 是 否只在這個地方買得到、是否代表了這個旅遊地, 另外, 伴手禮是否符合了美學的標準 (aesthetic)、是否有質感 (quality)、是否符合了實用 (use) 的原則、以及其旅程便 利性 (convenience) 為何, 都會影響消費者的購買意圖。

\section{2. 顧客的期望與認知品質}

\subsection{1. 顧客期望}

通常顧客期望被認為是「當顧客在購買產品之前對於 產品可以帶來的價值期望」。期望是影響滿意度的因素之 一，因為期望對於顧客形成有關產品或服務評價的判斷提 供參考標準 (馬承源, 2015) [11]。Boulding等人 (1993) [12] 認為顧客期望由許多不同層面所決定，依照不同情境與經 驗而成, 其提出一顧客期望之模型描述適當的期望水準須 考慮不同的因素, 從顧客的個人影響、商家的影響到情境 
環境的影響, 均會塑造顧客期望的形成 (Kurtz與 Clow, 1998) [13]。Boulding等人 [12]所提出的顧客期望定 義 $\lceil$ 認為顧客期望由許多不同層面所決定, 依照不同情境 不同經驗而成。」和本研究比較貼切, 因此, 本研究採用 作為顧客期望定義。

\subsection{2. 認知服務品質}

服務品質它的本質是無形的，所以一直以來就都是一 個模糊且難定義的構念, Parasuraman等人 (1985) [14]（以 下簡稱為PZB) 認為「品質是由期望和績效比較而得來」所 以對於認知品質 (perceived quality) 的衡量先提出的 PZB服務品質缺口 (gap) 模式, 再提出SERVQUAL量表的五大 服務構面評估模式: (1) 有形性 (tangibles) (2) 可靠性 (reliability) (3) 反應性 (responsiveness) (4) 保證性 (assurance) (5) 同理心 (empathy)。

\section{3. 顧客滿意度定義與構面}

Cardozo (1965) [15] 最早將顧客滿意的概念引進到行 銷學的範疇, 他認為良好的顧客滿意會增加消費者再購行 為。Park等人 (2004) [16]將滿意度的概念應用在消費者理 論中, 討論顧客對購買產品的付出與實際獲得的報酬是否 達到滿足的心理狀態。所以消費者滿意度是在購買消費後 所產生的感受, 而且是在購買該商品或實際體驗過服務後, 加以評估的反應結果。Parasuraman等人 (1994) [17]主張 顧客交易的整體滿意是對服務品質、產品品質與價格三者 評估所構成的函數關係。Zeitham1與Binter-(1996) [18] 明確指出顧客滿意的構面, 包括產品品質、服務品質、情 境因素、個人因素、價格。符合機場航廈的伴手禮大街的 情境與旅客旅行特性, 符合本研究內容, 因此本研究採用 其衡量構面作為研究問卷的顧客滿意度構面。

\section{4. 忠誠度定義與構面}

Forne11 (1992) [19] 認為忠誠度 (loyalty) 是由三種 因素所結合而成, 「顧客滿意度」、「轉換的障礙」、「顧 客的聲音」所形成的。Gronhold等人 (2000) [20]將顧客忠 誠區分為: 顧客的再購意願、向他人推薦、價格容忍度、 顧客交叉購買意願（購買同一公司其他產品的意願）。 01iver (1999) [21]對顧客忠誠度所下定義：「一種對於喜 好產品或服務在未來有再次購買的承諾, 亦表示顧客忠誠 度乃是顧客與銷售者之間將會有持續性往來。」。因此, 顧客忠誠被定義為顧客購買行為的連續性, 指客戶對企業 產品或服務的依賴和認可、堅持長期購買和使用該企業產 品或服務所表現出的在思想和情感上的一種高度信任和 忠誠的程度, 是客戶對企業產品在長期競爭中所表現出的 優勢的綜合評價。

有關忠誠度的構成因素，Jacoby與Kyner（1973）［22］ 提出以態度忠誠與行為忠誠做為衡量顧客忠誠度的兩個 構面。O1iver (1999) [23]再將顧客忠誠強弱區分為四個階 段, 即認知忠誠 (cognitive)、情感忠誠 (affective)、行 為意圖忠誠 (conative)、行動忠誠 (action), 主張嶅清各 階段忠誠度的意涵跟缺失, 才能有效地探討顧客忠誠度是 否會去影響行銷。

\section{5. EPSI}

Forne11等人（1996）[24] 認為美國消費者滿意度指標 （ACSI）具備的優點包括: 更加的滿意度可靠性、增加了 消費者期望因素、提高品質滿意度的比重。但在ACSI的衡 量構面裡面並未討論到商品本身與企業形象, 所以由EPSI Rating Group依據歐盟委員會要求提出修訂版之滿意度 架構, 稱為EPSI (Extended Performance Satisfaction Index) [25], 與ACSI的差別在於EPSI的架構中將商品本身 加入到架構中討論, 將認知品質 (硬體、軟體)一同討論, 因此本研究選用EPSI作為衡量構面。模式架構共有七個潛 在變項 [25], 包含企業形象、顧客期望、商品本身、認知 品質、顧客認知價值、顧客滿意與顧客忠誠。Eklöf與 Westlund (2002) [26] 提出EPSI的基準 (Master) 模型架構, 認為滿意度指標是唯一影響忠誠度的前因因素, 對於EPSI 的複雜架構予以精簡。本研究針對陸客對於桃園機場二期 航廈的伴手禮做研究在問卷衡量構面上須討論到商品本 身因此本研究參考採用EPSI作為衡量的架構, 但省略認知 價值構面, 以精簡問卷內容, 提高受訪者的答題意願。

\section{3. 研究方法}

\section{1. 研究假說及架構}

本研究參考EPSI的企業形象、旅客期望、商品品質、 服務品質、認知價值、滿意度、及忠誠度的因果關係 [25, 26], 設立相關的研究假設及模型架構 (圖1) 如後:

假說一 (H1) : 企業形象對於旅客認知價值、旅客滿意 度有顯著直接影響。

假說二 (H2) : 旅客期望對於旅客認知價值、旅客滿意 度有顯著直接影響。

假說三 $(\mathrm{H} 3)$ : 商品本身對於旅客認知價值、旅客滿意 度有顯著直接影響。

假說四 (H4): 認知服務品質對於旅客認知價值、旅客 滿意度有顯著直接影響。

假說五 (H5): 旅客認知價值對於旅客滿意度有顯著直 接影響。

假說六 (H6): 旅客滿意度對於旅客忠誠度有顯著直接 影響。

\section{2. 問卷設計}

本研究以問卷調查為主, 探討調查桃園機場二期航廈 伴手禮大街購物的大陸旅客與日本旅客, 瞭解他們購物動 機、伴手禮大街行銷活動與對伴手禮大街滿意度。在研究 設計上, 先根據文獻分析與研究目的擬定問卷, 再以桃園 機場二期航廈伴手禮大街購物的大陸旅客與日本旅客為 研究對象進行問卷調查法; 資料蒐集完成後, 進行問卷的 整理、分析與歸納。

問卷調查法共設計問卷量表有二部分, 分別為:

第一部分: 基本人口統計變項。包括1. 性別 2. 國別、 3. 年齡、4. 學歷背景、 5. 收入、6. 旅遊目的、7. 出國旅遊 次數、8. 預期購買伴手禮數量。 
第二部分: 根據在伴手禮大街購物的情境, 依據架構 SERVQUAL品質量表與EPSI架構來設計各項構面之問項, 共 計51題核心問項。

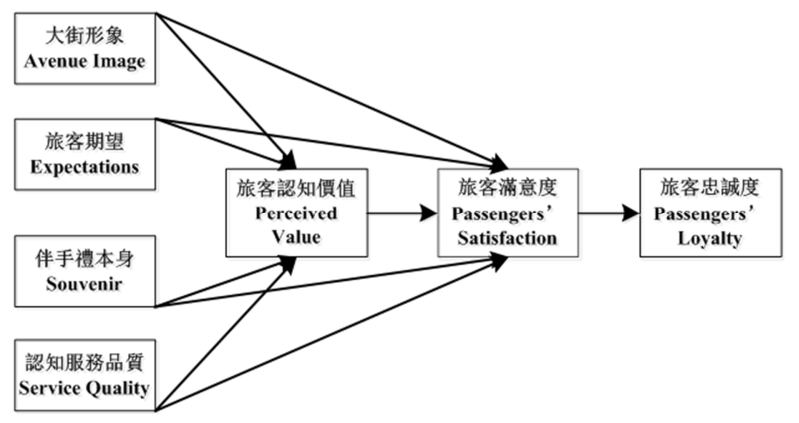

图1 研究模型架構圖。

\section{4. 研究結果}

\section{1. 樣本人口統計結構、因素分析、信度分析}

本研究問卷發放時間為今年九月 10 日至19日，總共發 放 120 份問卷, 回收份共 120 分, 剔除掉作答不清或不完整 之問卷共 4 份, 總計獲得有效問卷 116 份, 有效問卷填答率 99\%。本研究中旅客的基本資料, 包含性別、國籍、年龄 層、婚姻狀況、教育程度和平均收入等。

本研究回收問卷中, 受訪者年齡主要分佈在 $20 \sim 30$ 歲 (47. 4\%), 以已婚人口 (63.8\%) 和女性居多 (58\%), 教育程 度平均為專科/大學 $(67.2 \%)$ 最多, 而年收入平均為 3 萬元 台幣以下 $(37.1 \%)$ 為主。分別彙整如表1所示。

表1 受訪旅客基本資料統計表。

\begin{tabular}{|c|c|c|c|}
\hline 項目 & 分類 & 人數 & 比例 $(\%)$ \\
\hline \multirow{2}{*}{ 性別 } & 男性 & 49 & $42 \%$ \\
\hline & 女性 & 67 & $58 \%$ \\
\hline \multirow[t]{2}{*}{ 國籍 } & 中國大陸 & 116 & $100 \%$ \\
\hline & 20 (含)以下 & 13 & $11.2 \%$ \\
\hline \multirow{4}{*}{ 年齡層 } & 21 30歲 & 55 & 47. $4 \%$ \\
\hline & 31 40歲 & 24 & $20.7 \%$ \\
\hline & 41 50歲 & 17 & $14.7 \%$ \\
\hline & 51歲及以上 & 7 & $6 \%$ \\
\hline \multirow{2}{*}{ 婚姻狀況 } & 未婚 ～ & 42 & $36.2 \%$ \\
\hline & 已婚 & 74 & $63.8 \%$ \\
\hline \multirow{4}{*}{ 教育程度 } & 國中 (含)以下 & 0 & $0 \%$ \\
\hline & 高中(職) & 27 & $23.3 \%$ \\
\hline & 專科/大學 & 78 & $67.2 \%$ \\
\hline & 研究所及以上 & 11 & $9.5 \%$ \\
\hline \multirow{6}{*}{$\begin{array}{l}\text { 平均月收入 (台 } \\
\text { 幣) }\end{array}$} & 2萬以下 & 15 & $12.9 \%$ \\
\hline & 2 3萬 & 27 & 23. $3 \%$ \\
\hline & $3 \sim 5$ 萬 & 43 & $37.1 \%$ \\
\hline & 5 7萬 & 25 & $21.6 \%$ \\
\hline & 7 9萬 & 4 & $3.4 \%$ \\
\hline & 9萬以上 & 2 & $1.7 \%$ \\
\hline
\end{tabular}

受訪者於機場航廈內的相關資料, 包含此次旅行目的、 每年出國次數、預期購買伴手禮的數量。本研究回收問卷 中，大部分皆為出國目的以旅遊為主 (98\%)，每年平均出
國頻率以1 2次為最高 (80.2\%), 預計購買伴手禮的數量為 7. 5 為平均值，詳細的旅客出國經驗分別彙整如表2所示。

表2 旅客出國經驗資料統計表。

\begin{tabular}{llll}
\hline 項目 & 分類 & 人數 & 比例 (\%) \\
\hline \multirow{3}{*}{ 旅行目的 } & 旅遊 & 114 & $98 \%$ \\
& 商(公) 務 & 1 & $1 \%$ \\
& 探親 & 1 & $1 \%$ \\
& 其他 & 0 & $0 \%$ \\
& 1 2次 & 93 & $80.2 \%$ \\
每年出國次數 & 3 5次 & 16 & $13.8 \%$ \\
& 5次以上 & 7 & $6 \%$ \\
\hline
\end{tabular}

本研究使用spss. 21軟體進行因素構面內的變數問項 信度 (reliability) 分析及後續的因素關聯迴歸分析。採 用Cronbach’ s a 係數衡量信度水平, Hair等人 [27]指出 一般信度值 $\alpha>0.7$ 代表具有適當信度，0.7> $\alpha>0.6$ 尚可接 受, 在範圍內皆可稱為有信度之問卷。研究構面之問項信 度分別彙整如表3。

\section{2. 迴歸分析}

\section{2. 1. 旅客認知價值的直接影響因素}

本節迴歸分析 (Regression) 是將企業形象、旅客期望、 商品本身及認知品質五項構面定義為自變數, 旅客認知價 值為依變數, 將問卷原始數據進行分析, 結果展現於表 4 與表5。

表4顯示 $R^{2}$ 判定係數（Coeff. of Determination）是 $0.889, F$ 檢定之 $p$ 值 $=0.000<0.05$, 達到顯著水準, 表示形 象、期望、商品本身、認知品質對於旅客認知價值具有整 體正面的影響，因此多元迴歸模式架構具備顯著成立特 性。

有關個別因素構面之影響, 表5 的 $t$ 檢定顯示企業形象 與旅客認知價值之間沒有顯著關係 $(p=0.237>0.05)$; 旅客 期望與認知價值之間呈現顯著的正向關係 ( $\beta=0.188$, $p=0.002<0.05)$; 商品本身與認知價值之間沒有顯著的關 係 $(p=0.486>0.05)$; 服務有形性與認知價值之間呈現顯著 的關係 $(\beta=0.159, p=0.013<0.05)$; 服務可靠性與認知價 值之間呈現顯著正向關係 $(\beta=-0.159, p=0.041>0.05)$; 服 務反應性與認知價值之間呈現顯著正向關係 $(\beta$ $=0.273, p=0.000<0.05)$; 服務保證性與認知價值之間呈現 顯著正向關係 $(\beta=0.298, p=0.000<0.05)$; 服務同理心與 認知價值之間呈現顯著的正向關係 $(\beta=0.26$, $p=0.000<0.05)$ 。

旅客認知價值的前因構面裡, 旅客期望、有形性、可 靠性、反應性、保證性、同理心具有顯著的影響。表5也 用來觀察影響因素是否有共線性 (multicollinearity), 允差值介於 0 與 1 之間。當允差低於 0.1 時, 表示自變項間 的共線性情況需要關注 [27]。表 5 中的允差皆大於 0.1 以上, 顯示各自變數因素之間並無明顯共線性問題存在。 
表3 研究構面問項信度分析。

\begin{tabular}{lll}
\hline 因素構面 & Cronbach' $\mathrm{s} \alpha$ & 構面變數項數 \\
\hline 企業形象 & 0.875 & 5 \\
旅客期望 & 0.881 & 5 \\
商品本身 & 0.824 & 4 \\
商店有形性 & 0.894 & 4 \\
服務可靠性 & 0.903 & 5 \\
服務反應性 & 0.849 & 4 \\
服務保證性 & 0.921 & 5 \\
服務同理心 & 0.916 & 4 \\
旅客認知價值 & 0.910 & 5 \\
旅客滿意度 & 0.866 & 5 \\
旅客忠誠度 & 0.833 & 5 \\
\hline
\end{tabular}

\subsection{2. 旅客滿意度的直接影響因素}

依據研究架構, 將形象、期望、商品本身、認知品質 5 構面及認知價值因素定義為自變數, 旅客忠誠度為依變 數，進行迴歸之分析。表 6 顯示 $R^{2}$ 是 $0.786, p=0.000<0.05$, 達到顯著水準, 表示多元迴歸模式架構具備顯著特性。

表7數據顯示前因構面中與旅客滿意度呈現顯著關係 的自變因素包括旅客期望 $(\beta=0.208, p=0.007<0.05)$ 、有 形性 $(\beta=0.181, p=0.022<0.05)$ 、可靠性 $(\beta=-0.346$, $p=0.000<0.05)$ 、認知價值 $(\beta=0.724, p=0.000<0.05)$ 等四 項。另一方面, 與旅客滿意度之間未呈現顯著關係的因素 包括形象、商品本身、反應性、保證性及同理心等五項 $(\mathrm{p}$ $>0.05)$ 。表 7 中的允差皆大於 0.1 以上, 顯示各自變數因素 之間並無明顯共線性問題存在。

表4 旅客認知價值迴歸模式檢定。

\begin{tabular}{llllll}
\hline $\mathrm{R}$ & $\mathrm{R}^{2}$ & 調整後 $\mathrm{R}^{2}$ & $\mathrm{~F}$ 檢定 & $\mathrm{p}$-值 & Durbin-Watson \\
\hline 0.943 & 0.889 & 0.880 & 106.901 & $0.000 * * *$ & 2.186 \\
\hline
\end{tabular}

表5 旅客認知價值迴歸係數檢定。

\begin{tabular}{|c|c|c|c|c|c|c|c|}
\hline & \multicolumn{2}{|c|}{ 非標準化係數 } & \multirow{2}{*}{$\begin{array}{l}\text { 標準化 } \\
\text { 係數 } \\
\text { Beta }\end{array}$} & \multirow{2}{*}{$\begin{array}{l}t \\
\text { 檢定 }\end{array}$} & \multirow{2}{*}{$p$-值 } & \multicolumn{2}{|c|}{ 共線性 } \\
\hline & $\begin{array}{l}\beta \text { 估 } \\
\text { 計值 }\end{array}$ & $\begin{array}{l}\text { 標準 } \\
\text { 誤差 }\end{array}$ & & & & 允差 & VIF \\
\hline 常數 & -.207 & .272 & & -.761 & .448 & & \\
\hline $\begin{array}{l}\text { 企業形 } \\
\text { 象 }\end{array}$ & .069 & .058 & .062 & 1. 190 & .237 & 383 & 2. 609 \\
\hline $\begin{array}{l}\text { 旅客期 } \\
\text { 望 }\end{array}$ & .188 & .060 & .173 & 3. 134 & .002 & 343 & 2. 920 \\
\hline $\begin{array}{l}\text { 商品本 } \\
\text { 身 }\end{array}$ & -.036 & .052 & -.030 & -.700 & .486 & .567 & 1. 765 \\
\hline 有形性 & .159 & .063 & .157 & 2. 514 & .013 & .266 & 3. 762 \\
\hline 可靠性 & -. 159 & .077 & -.144 & -2.073 & .041 & .216 & 4.635 \\
\hline 反應性 & .273 & .066 & .257 & 4. 144 & .000 & .270 & 3. 708 \\
\hline 保證性 & .298 & .080 & .278 & 3. 704 & .000 & .184 & 5. 424 \\
\hline 同理心 & .260 & .049 & .296 & 5.330 & .000 & .337 & 2. 971 \\
\hline
\end{tabular}

表6 旅客滿意度迴歸模式檢定。

\begin{tabular}{llllll}
\hline $\mathrm{R}$ & $\mathrm{R}^{2}$ & 調整後 $\mathrm{R}^{2}$ & $\mathrm{~F}$ 檢定 & $\mathrm{p}$-值 & Durbin-Watson \\
\hline 0.886 & 0.786 & 0.768 & 43.204 & 0.000*** & 2.323 \\
\hline
\end{tabular}

表7 旅客滿意度迴歸係數檢定。

\begin{tabular}{|c|c|c|c|c|c|c|c|}
\hline & \multicolumn{2}{|c|}{$\begin{array}{l}\text { 非標準化 } \\
\text { 係數 }\end{array}$} & \multirow{2}{*}{$\begin{array}{l}\text { 標準化 } \\
\text { 係數 } \\
\text { Beta }\end{array}$} & \multirow{2}{*}{$\begin{array}{l}t \\
\text { 檢定 }\end{array}$} & \multirow{2}{*}{$p$-值 } & \multicolumn{2}{|c|}{ 共線性 } \\
\hline & $\begin{array}{l}\beta \text { 估 } \\
\text { 計值 }\end{array}$ & $\begin{array}{l}\text { 標準 } \\
\text { 誤差 }\end{array}$ & & & & 允差 & VIF \\
\hline 常數 & 1.735 & .326 & & 5.323 & .000 & & \\
\hline $\begin{array}{l}\text { 企業形 } \\
\text { 象 }\end{array}$ & .074 & .070 & .078 & 1. 063 & .290 & .378 & 2. 643 \\
\hline $\begin{array}{l}\text { 旅客期 } \\
\text { 望 }\end{array}$ & .208 & .075 & .223 & 2.776 & .007 & .314 & 3. 188 \\
\hline $\begin{array}{l}\text { 商品本 } \\
\text { 身 }\end{array}$ & -.066 & .062 & -.064 & -1.063 & .290 & .564 & 1. 773 \\
\hline 有形性 & .181 & .078 & .209 & 2.326 & .022 & .251 & 3. 984 \\
\hline 可靠性 & -.346 & .094 & -.365 & -3.700 & .000 & .207 & 4. 822 \\
\hline 反應性 & -. 129 & .085 & -.142 & -1.525 & .130 & .232 & 4. 303 \\
\hline 保證性 & -.001 & .102 & -.001 & -.008 & .994 & .163 & 6. 120 \\
\hline 同理心 & .036 & .066 & .047 & .542 & .589 & .266 & 3. 759 \\
\hline $\begin{array}{l}\text { 認知價 } \\
\text { 值 }\end{array}$ & .724 & .116 & .844 & 6.261 & .000 & .111 & 8.993 \\
\hline
\end{tabular}

\subsection{3. 旅客忠誠度的直接影響因素}

將旅客滿意度定義為單一自變因素, 而旅客忠誠度為 依變數, 其迴歸分析結果顯示於表 8 及表 9 。表 8 顯示 $R^{2}$ 是 0.553, $p=0.000<0.05$, 達到顯著水準， $\beta=0.813$, 表示 旅客滿意度與忠誠度具有顯著正面的影響, 無法拒絕H6, 因此假設獲得成立。

表8 旅客忠誠度迴歸模式檢定。

\begin{tabular}{llllll}
\hline $\mathrm{R}$ & $\mathrm{R}^{2}$ & 調整後 $\mathrm{R}^{2}$ & $\mathrm{~F}$ 檢定 & $\mathrm{p}$-值 & Durbin-Watson \\
\hline 0.743 & 0.553 & 0.549 & 140.790 & $0.000 * * *$ & 1.803 \\
\hline
\end{tabular}

表9 旅客忠誠度迴歸係數檢定。

\begin{tabular}{|c|c|c|c|c|c|c|c|}
\hline & \multicolumn{2}{|c|}{ 非標準化係數 } & \multirow{2}{*}{$\begin{array}{l}\begin{array}{l}\text { 標準化 } \\
\text { 係數 }\end{array} \\
\text { Beta }\end{array}$} & \multirow{2}{*}{$\begin{array}{l}t \\
\text { 檢定 }\end{array}$} & \multirow{2}{*}{$p$-值 } & \multicolumn{2}{|l|}{ 共線性 } \\
\hline & $\begin{array}{l}\beta \text { 估 } \\
\text { 計值 }\end{array}$ & $\begin{array}{l}\text { 標準 } \\
\text { 誤差 }\end{array}$ & & & & 允差 & VIF \\
\hline 常數 & .933 & .402 & & 2.323 & 022 & & \\
\hline 滿意度 & 813 & 069 & .743 & 11.866 & .000 & 1. 000 & 1.000 \\
\hline
\end{tabular}

\section{5. 結論與建議}

本研究是探討在桃園機場第二期航廈伴手禮大街的服 務品質與伴手禮商品是否能夠滿足大陸來台旅客之需求。 依據微調的EPSI研究架構與SERVQUAL品質構面, 進行問卷 設計, 研究方法則採用複迴歸分析。本研究架構包括六項 假設, 其中獲得成立的假設為H2、H5及H6; 部分成立的假 設為H4；無法成立的假設有H1及H3。受訪之大陸旅客對於 伴手禮大街的旅客認知價值會有下列因素影響, 包括旅客 期望、服務有形性、服務可靠性、服務反應性、服務保證 性及服務同理心。旅客滿意度會受到旅客期望、有形性、 可靠性及認知價值等因素的影響。至於旅客忠誠度，單一 滿意度因素的判定係數 $\left(R^{2}\right)$ 達到 0.553 , 代表忠誠度的總誤 差變異量, 可以經由滿意度做適當的詮釋, 其 $\beta$ 係數為 0.813 。 至於伴手禮大街形象與商品本身兩項因素, 似乎對於受訪 者無法產生明顯之影響, 需要進一步後續分析。 
在建議的部分, 由於施測的地點位於伴手禮大街, 多 數的旅客為團體客居多, 在發放問卷時受限於須先徵求領 隊或是導遊的同意才可發放問卷, 建議未來可參考是否尋 求旅行社的配合來增加問卷的數量。另外, 本次研究僅考 慮所購買的伴手禮數量, 對於旅客所購買的伴手禮類別並 未納入考量, 建議未來可針對此部分新增進行討論。

\section{参考文献}

[1] 天下, 545期「旅遊業邁入黃金十年！中國成最大旅遊市場」 [J]，2014，545。擷取日期：2016年1月17日，網站： http://www. cw. com. tw/article/article. action?id=505 7382 。

[2] Traveladvertiser「聯合國世界旅遊組織報告：2014年有 超過1. 1億人出國旅遊！」[Z], 2015。擷取日期: 2016年1 月 17 日 ，網站 : https://christyroyal jetway. wordpress. com/2015/02/2 $0 /$ 。

[3] Global Airport Retailing : Market Size, Retailer Strategies and Competitor Performance [R], 2012。擷 取日期： 2016 年 01 月 18 日，網站： http://www. slideshare. net/VerdictRetail/global-air port-retailing-sample-pages 。

[4] 中央通訊社, 「2016台灣伴手禮名品展」商機看俏11月底前 報名享優惠 $[Z], 2015$ 。擷取日期: 2015年12月30日，網站： http://www. cna. com. tw/postwrite/Detail/177563. aspx \#. Vo8XasEVHIU。

[5] 美食滔客, 2015, 亞洲遊客來台最愛十大伴手禮 $[Z]$, 擷取 日 期： 2015 年 12 月 29 日，網 站 : http://tasty. talk. tw/Article. aspx?Article_ID=243。

[6] 陳明國、陳信榕、劉巧雯, 伴手禮購買行為之研究 $[J]$, 運 動休閒管理學報, 2013，10(4)，64-77。

７］簡南山、賴宏榮, 最佳伴手禮的屬性分析之研究 $[C]$, 第 10 屆管理學域國際學術研討會論文集, 台中: 朝陽科技大學, 2009, 159-174。

[8] 林雅涵, KANO模式應用於伴手禮品質改善之研究 [D], 高雄 市, 國立高雄應用科技大學觀光與餐旅管理研究所, 2014。

[9] Litire11, M. A., Baizerman, S., Kean, R., Gahring, S. Niemeyer, S., Reilly, R., \& Stout, J., Souvenirs and Tourism Styles[J]. Journal of Travel Research, 1994, $33(1), 3-11$.

[10] Turner, L. W. \& Reisinger, Y., Shopping satisfaction for domestic tourists $[\mathrm{J}]$. Journalof Retailing and Consumer Services, 2001, 8(1), 15-27.

[11］馬承源，住宿者期望及滿意度對再宿意願之影響－以溪頭 民宿顧客為例 $[D]$, 彰化縣, 大葉大學休閒休閒事業管理學 系碩士班，2015。
[12] Boulding, W., Kalra, A., Staelin, R., \& Zeithaml, V. A., A Dynamic Process Model of Service Quality: From Expectations to Behavioral Intentions [J]. Journal of Marketing Research, 1993, 30(1), 7-27.

[13] Kurtz, D. L. \& Clow, K. E., Services Marketing [M]. John Wiley \& Sons. Inc., 1997, 35-56.

[14] Parasuraman, A. , Zeithaml, V. A. \& Berry, L. L. , SERVQUAL: A Multiple-Item Scale for Measuring Consumer Perception of Service Quality [J]. Journal of Retailing, 1988, 64(1), 12-40.

[15] Cardozo, R. N., An Experimental Study of Customer Effort, Expectation, and Satisfaction $[\mathrm{J}]$. Journal of Marketing Research, 1965, 2(3), 244-249.

[16] Park, J.-W., Robertson, R., \& Wu, C. -L., The Effect of Airline Service Quality on Passengers' Behavioural Intentions: a Korean Case Study [J]. Journal of Air Transport Management, 2004, 10, 435-439.

[17] Parasuraman, A., Zeithamal, V. A. \& Berry, L. L., Reassessment of Expectations as A Comparison Standard in Measuring Service Quality: Implications for Further Research [J]. Journal of Marketing, 1994, 58, 111-124.

[18] Zeithaml, V. A. \& Bitner, M. J., Service Marketing [M]. McGraw-Hi11, 1996.

[19] Fornel1, C., A National Customer Satisfaction Barometer: The Swedish Experience [J]. Journal of Marketing, 1992, 56(1), 6-21.

[20] Gronhold, L., Martensen, A., \& Kristensen, K., The Relationship between Customer Satisfaction and Loyalty: Cross-Industry Differences [J]. Total Quality Management, 2000, 11(4-6), 509-514.

[21] 0liver, R. L., Measurement and Evaluation of Satisfaction Processes in Retailing Settings [J]. Journal of Retailing, 1981, 57 (3), 25-48.

[22] Jacoby, J. \& Kyner, D. B., Brand Loyalty vs. Repeat Purchasing Behavior $[\mathrm{J}]$. Journal of Marketing Research, 1973, 10(1), 1-9.

[23] 0liver, R. L., Whence Consumer Loyalty? [J]. Journal of Marketing, 1999, 63 (Special Issue): 33-44.

[24] Forne11, C. , Johnson, M. D., Anderson, E. W. , Cha, J. , \& Bryant, B. E., The American Customer Satisfaction Index: Nature, Purpose, and Findings [J]. Journal of Marketing, 1996, 60(4), 7-18.

[25] Eskildsen, J., Kristensen, K., Juh1, H. J. , \& 0stergaard, P. The Drivers of Customer Satisfaction and Loyalty. The Case of Denmark 2000-2002 [J]. Total Quality Management, 2004, 15(5-6), 859-868. 
[26] Eklöf, J. A. \& Westlund, A. H., The Pan-European Customer Satisfaction Index Programme-Current Work and Way Ahead [J]. Total Quality Management, 2002, 13 (8), 1099-1106.
[27] Hair, J. F., Black, W. C., Babin, B. J., \& Anderson, R. E., Multivariate Data Analysis: A Global Prespective (7/e) [M], New Jersey: Pearson Prentice-Hall, 2010. 